\title{
Investigation of the effect of the amount of film- forming coatings based on natural biopolymers on the quality characteristics of grape berries
}

\author{
Sergey Gorlov ${ }^{1}$, Yatsushko Ekaterina ${ }^{2}$, Tatiana Pershakova ${ }^{2}$, Tatiana Yakovleva ${ }^{2 *}$, and \\ Vladimir Aleshin ${ }^{2}$ \\ ${ }^{1}$ Federal State Budget Scientific Institution «North Caucasian Federal Scientific Center of Horticulture, \\ Viticulture, Wine-making», 39 str. 40 Let Pobedy, Krasnodar, 350901, Russia \\ ${ }^{2}$ Krasnodar Research Institute of Agricultural Products Storage and Processing - branch of FSBSO \\ "North-Caucasian Federal Scientific Center of Horticulture \& Viniculture", st. Topolinaya alleya, 2, \\ Krasnodar, 350072, Russia
}

\begin{abstract}
Post-harvest losses of grapes during prolonged storage in refrigerated chambers are mainly associated with dehydration and darkening of stems, wilting of berries and the development of mold. As a result of the physiological processes in the berries, a sufficiently humid environment is created, which contributes to the development of microbiological spoilage. To combat this phenomenon, it is recommended to use natural biodegradable polymers, which prevent the deterioration of quality characteristics by creating a semi-permeable protective barrier. In this regard, the purpose of the study was to determine the optimal dosage of film-forming solutions for treatment of grapes. For this, samples of grapes of the Kishmish Luchistyi variety were prepared with an applied to the surface coating layer of two types: potato starch/gelatin/glycerin/ natamycin and chitosan/sodium alginate/glycerin/natamycin at a biopolymer ratio of $50 / 50 \%$, with the addition of $1.3 \%$ glycerin and $0.3 \%$ natamycin. Based on the identified dependence of the weight loss and the value of the resistance of berries to the pressure force on the storage time and the amount of film-forming coating, the optimal amount of film-forming coating required to treat 1000 grams of berries is substantiated $-50 \mathrm{ml}$.
\end{abstract}

\section{Introduction}

At the enterprises of wholesale and retail trade and public catering, storage conditions for grapes received for sale from a stationary storage or directly from agricultural producers are not always optimal. In this regard, additional treatment is required to reduce the amount of losses from wilting, microbiological deterioration and mechanical damage. Film-forming coatings, which are thin edible layers applied to food products, can become a tool for reducing losses and extending the shelf life of grapes [1,2].

\footnotetext{
*Corresponding author: yakovleva_yy@mail.ru
} 
Chitosan, cellulose, sodium alginate, carrageenan, zein, gluten, starch, gelatin and fatty acids are the most commonly used compounds to form edible stabilizing coatings for fruits, vegetables, meat and fish products [3-11].

For example, the authors [6] investigated the physicochemical properties of edible films based on cuttlefish skin gelatin, extracted without or with various concentrations of pepsins. Edible films made with partially hydrolyzed gelatins had lower tensile strength and elongation at break, but higher water vapor permeability and water solubility than the control film.

The authors [9] have developed films based on cassava starch, 25 and 50\% (in a polymer mixture) bovine gelatin using glycerin $(30 \%)$ as a plasticizer. Film formulations were also made with 15\% lipids (a mixture of esters from fatty acids and glycerol). The authors found that the inclusion of gelatin and lipids in glycerin-plasticized cassava starch films markedly affected their physical properties; treatment with $30 \mathrm{mg}$ per 1000 grams of apples showed the best results.

The authors [12] studied thin coatings for extending the shelf life of foods made using starch, which can be used in combination with antimicrobial agents. Their work was aimed at the development and characterization of a nanoemulsion of oleic acid in a food coating based on a starch suspension with the inclusion of three natural antimicrobials in the mixture: lactic acid, nisin, and lauric arginate. The authors found that the resulting suspensions can be used as coatings to extend the shelf life of fresh foods.

With regard to the use of coatings on grapes, their effectiveness as a post-harvest treatment in order to extend shelf life and maintain quality, especially to reduce overall weight loss, has been confirmed by several studies [2, 4, 13-15], most of which offer commercial use of the results. For example, the authors [4] have developed and studied the physicochemical properties of composite films based on corn starch and gelatin, plasticized with glycerin or sorbitol for application to the surface of grapes. The addition of gelatin was found to significantly increase mechanical strength, water solubility, water vapor permeability and biofilm thickness, and also reduced opacity; the most effective was the treatment of grapes with $60 \mathrm{ml}$ of solution per $1000 \mathrm{~g}$ of berries.

In this regard, there is a need to evaluate different dosages of film-forming coatings based on natural edible and biodegradable biopolymers in order to determine cost-effective ways to improve food quality and safety during storage, maintain their freshness and extend shelf life.

\section{Materials and methods}

Table grapes of the Kishmish Luchisty variety, grown in the Anapo-Taman zone of the Krasnodar region in 2018 - 2020, were the object of research. For the preparation of filmforming solutions and films based on them, certain components were used: polymers (soluble starch (GOST 10163-76), food gelatin (GOST 11293-89), chitosan (CAS 9012-76-4), sodium alginate (CAS 9005-38-3)); a plasticizer (glycerin (GOST 6259-75)); a solvent (distilled water); an auxiliary substance (LNFY190906-31 natamycin produced by LLC "ALPLIK RUS").

Table 1 shows the composition and parameters of the preparation of samples of filmforming solutions.

The optimal dosage of film-forming solutions for the treatment of grapes was determined, which were pre-cooled to a temperature of $10^{\circ} \mathrm{C}$, treated with the selected variants of filmforming coatings with a temperature of $25^{\circ} \mathrm{C}$ by spraying with various dosages: 25,50 or $100 \mathrm{ml}$ per $1000 \mathrm{~g}$ of berries. To dry the film-forming solution and form a hard coating, the treated grape samples were dried at a temperature of $23 \pm 2{ }^{\circ} \mathrm{C}$, then placed in a refrigerator 
for 8 days at a temperature of 0 to $4{ }^{\circ} \mathrm{C}$ and an average relative humidity of $70-75 \%$. Control samples of grapes were not treated.

Experimental studies were carried out in triplicate; mathematical processing of experimental data was performed using Office Excel (Microsoft) for Windows and Statistica (StatSof Inc.).

Table 1. The composition and parameters of the preparation of film-forming solutions

\begin{tabular}{|c|c|c|c|}
\hline $\begin{array}{l}\text { Number } \\
\text { of } \\
\text { sample }\end{array}$ & \multicolumn{2}{|c|}{$\begin{array}{c}\text { Ratio of recipe components, } \\
\%\end{array}$} & Parameters of preparation \\
\hline \multirow{4}{*}{1} & Gelatin solution 5\% & 49,2 & \multirow{4}{*}{$\begin{array}{l}\text { Weighed portions of gelatin and starch powders } \\
\text { were separately poured with water at } 20^{\circ} \mathrm{C} \text { and } \\
\text { soaked for } 10 \text { min. Stirred at } 150 \mathrm{rpm} \text { for } 15 \\
\text { minutes. Then brewed with constant stirring at a } \\
\text { temperature of } 90^{\circ} \mathrm{C} \text { for the starch solution and } \\
60^{\circ} \mathrm{C} \text { for the gelatin solution for } 25 \text { minutes. } \\
\text { Glycerin and natamycin were added. Mixed and } \\
\text { homogenized with constant stirring for } 15 \text { min at a } \\
\text { temperature of } 70^{\circ} \mathrm{C}\end{array}$} \\
\hline & Starch solution 5\% & 49,2 & \\
\hline & Glycerin & 1,3 & \\
\hline & Natamycin & 0,3 & \\
\hline \multirow[t]{4}{*}{2} & Chitosan solution $1 \%$ & 49,2 & \multirow{4}{*}{$\begin{array}{l}\text { Weighed portions of chitosan and sodium alginate } \\
\text { were poured with water at } 20^{\circ} \mathrm{C} \text { and soaked for } 30 \\
\text { min. Stirred continuously at } 120 \mathrm{rpm} \text { for } 45 \mathrm{~min} \text { to } \\
\text { obtain a homogeneous solution. Glycerin and } \\
\text { natamycin were added. Mixed and homogenized } \\
\text { with constant stirring for } 15 \mathrm{~min} \text { at a temperature of } \\
70^{\circ} \mathrm{C}\end{array}$} \\
\hline & \begin{tabular}{|l|} 
Sodium alginate \\
solution $1 \%$
\end{tabular} & 49,2 & \\
\hline & Glycerin & 1,3 & \\
\hline & Natamycin & 0,3 & \\
\hline
\end{tabular}

\section{Results and discussion}

For weight loss analysis, samples treated with test coatings were weighed every day during storage. The dynamics of the weight loss of grapes during 8 days of storage is shown in the figure 1.

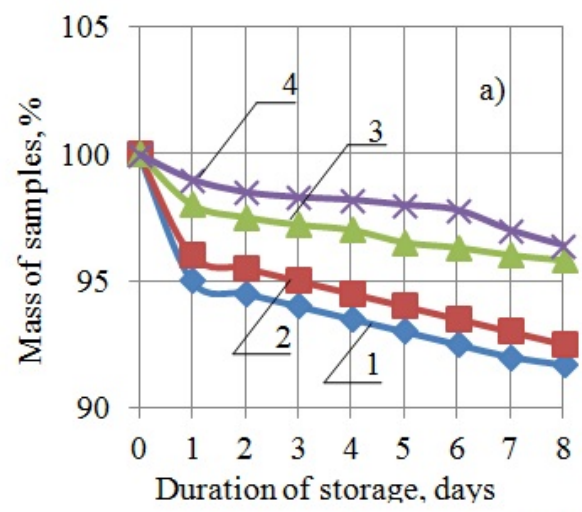

$$
1-\text { Control } \quad 2-25 \mathrm{ml}
$$

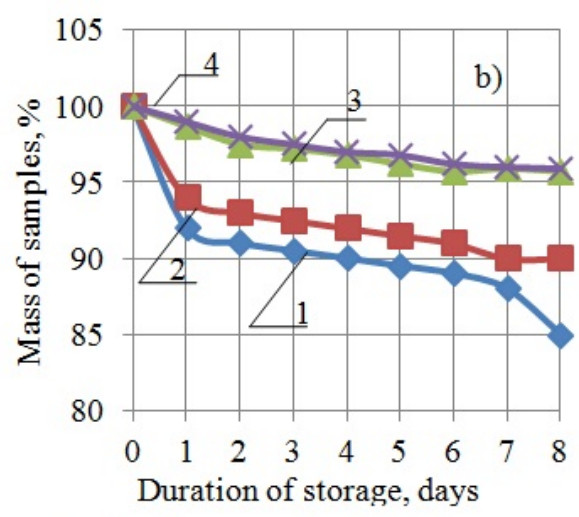

$3-50 \mathrm{ml} \quad 4-100 \mathrm{ml}$

Fig. 1. Weight loss versus test time and amount of film-forming coating based on combination:

a) starch / gelatin / glycerin / natamycin; b) chitosan / sodium alginate / glycerin / natamycin 
The effect of treating grape bunches with different amounts of a film-forming solution on the value of the resistance of the berries to the force of compression was also studied. The results are shown in the figure 2.

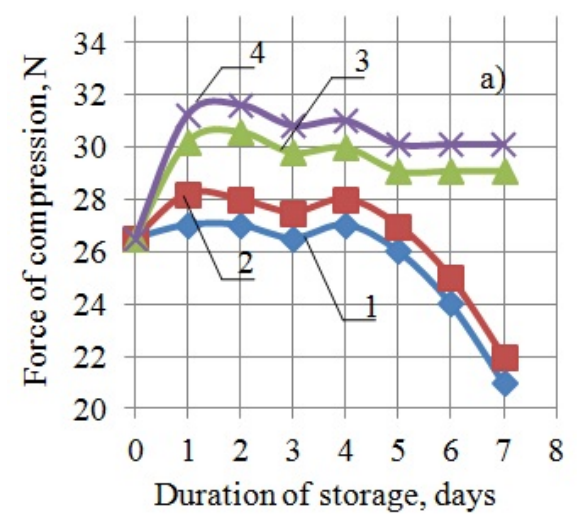

$1-$ Control $\quad 2-25 \mathrm{ml}$

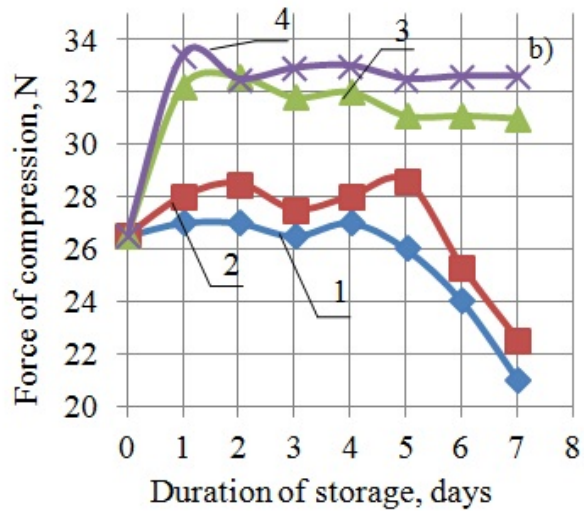

$3-50 \mathrm{ml} \quad 4-100 \mathrm{ml}$

Fig. 2. Value of the resistance of the berries to the force of compression versus test time and amount of film-forming coating based on combination:

a) starch / gelatin / glycerin / natamycin; b) chitosan / sodium alginate / glycerin / natamycin

The dependence shown in Figure 1 shows that storage of grapes in a humid atmosphere still leads to a decrease in the mass of the product. However, by studying the weight loss of the samples, it is possible to establish the optimal dosage of the applied coating. The smallest weight loss was recorded for samples treated with a film-forming coating at a dosage of 50 and $100 \mathrm{ml}$ per $1000 \mathrm{~g}$. Since there is no significant difference in weight loss between these dosages, a dosage of $50 \mathrm{ml}$ can be previously recommended for use. The final decision will depend on further research on mechanical strength.

It was also found (Figure 2) that the treatment of grape berries with film-forming coatings has a positive effect on the strength of the berries during storage: the studied samples of filmforming solutions provide an increase in the strength of berries at the end of storage in comparison with the control from $4.8 \%$ to $43.3 \%$ (solution based on polymer combination starch / gelatin / glycerin / natamycin) and from $7.1 \%$ to $55.2 \%$ (solution based on polymer combination chitosan / sodium alginate / glycerin / natamycin). Samples treated with 50 and $100 \mathrm{ml}$, compared to the control, showed a significant improvement in resistance to compression; the sample treated with $25 \mathrm{ml}$ showed little improvement.

\section{Conclusion}

Based on the study of the effect of the amount of film-forming coating on the dynamics of weight loss of grapes and the resistance of berries to the pressure force during long-term storage, it is necessary to note the positive effect of both preparations and recommend them for treatment of table grapes. The optimal dosage of a film-forming coating, which ensures the maximum preservation of quality of grapes, has been identified - $50 \mathrm{ml}$ per 1000 grams of berries by spraying the solution onto a bunch. 


\section{References}

1. M.Q. Carter, M.H. Chapman, F. Gabler, M.T. Brandla, Food Microbiol., 49, 189-196 (2015) https://doi.org/10.1016/j.fm.2015.02.002

2. C.D. Ingrid, D.L. Priscila, M.F. Miriane, A. Carneiro Lúcio, J. Fechine Tavares, Innov. Food Sci. Emer. Technol., 34, 112-121 (2016) https://doi.org/10.1016/j.ifset.2016.01.008

3. B.G. Laycock, P.J. Halley, In: P.J. Halley, L. Avérous (eds.) Starch Polymers, 381-419 (Elsevier, 2014) https://doi.org/10.1016/B978-0-444-53730-0.00026-9

4. F.M. Fakhouri, S.M. Martelli, T. Caon, J.I. Velasco, L.H. Innocentini Mei, Postharv. Bio. Technol., 109, 57-64 (2015) https://doi.org/10.1016/j.postharvbio.2015.05.015

5. G.F. Lemes, N.G. Marchiore, T.F. Moya Moreira, T.B. Vieira Da Silva, C. Sayer, M.A. Shirai, O.H. Gonçalves, A.M. Gozzo, F.V. Leimann, LWT, 84, 175-182 (2017) https://doi.org/10.1016/j.lwt.2017.05.050

6. M. Jridi, N. Souissi, A. Mbarek, G. Chadeyron, M. Kammoun, M. Nasri, Int. J. Biol. Macromol., 61, 17-25 (2013) https://doi.org/10.1016/j.ijbiomac.2013.06.040

7. E.A. Baldwin, R. Hagenmaier, J. Bai, Edible Coatings and Films to Improve Food (CRC Press, 2011) https://doi.org/10.1201/b11082

8. S.C. Shit, P.M. Shah, J. Polym., 2014, $427259 \quad$ (2014) https://doi.org/10.1155/2014/427259

9. S. Acosta, A. Jiménez, M. Cháfer, C. González-Martínez, A. Chiralt., Food Hydrocoll., 49, 135-143 (2015) https://doi.org/10.1016/j.foodhyd.2015.03.015

10. J. Correa-Betanzo, J.K. Jacob, C. Perez-Perez, G. Paliyath, Food Res. Int., 44, 1897-1904 (2011) https://doi.org/10.1016/j.foodres.2010.10.053

11. M.G. Farias, F.M. Fakhouri, C.W. Piler de Carvalho, J.L. Ramirez Ascheri. Quim. Nova, 35, 546-552 (2012) https://doi.org/10.1590/S0100-40422012000300020

12. I. Sánchez-Ortega, B.E. García-Almendárez, E. M. Santos-López, L.R. Reyes-González, C. Regalado. Food Hydrocoll., 52, 906-913 (2016) https://doi.org/10.1016/j.foodhyd.2015.09.004

13. Y.A. Oh, Y.J. Oh, A.Y. Song, J.S. Won, K.B. Song, S.C. Min, LWT, 75, 742-750 (2017) https://doi.org/10.1016/j.lwt.2016.10.033

14. A.A. Lo'ay, N.A. Taha, Y.A. EL-Khateeb, Sci. Hortic., 249, 314-321 (2019) https://doi.org/10.1016/j.scienta.2019.02.014

15. C.L. Luchese, J.C. Spada, I.C. Tessaro, Ind. Crops Prod., 109, 619-626 (2017) https://doi.org/10.1016/j.indcrop.2017.09.020 